\title{
Fungi carried over in jute bags - a smoking gun for aflatoxin contamination in the food supply chain
}

\author{
C. Wang ${ }^{1 *}$, F. Xu ${ }^{1}$, R.C. Baker ${ }^{1}$, A. Pinjari ${ }^{2}$, L. Bruckers ${ }^{3}$, Y. Zhao ${ }^{1}$, A. Stevenson ${ }^{1}$ and G. Zhang ${ }^{*}$ \\ ${ }^{1}$ Mars Global Food Safety Center, Mars Inc., Yanqi Economic Development Zone, Huairou, Beijing 101407, China P.R.; \\ ${ }^{2}$ Mars International India Pvt, Ltd, Avusulonipally village, Wargal Mandal, Siddipet Distt. Telangana State, 502279, India; \\ ${ }^{3}$ Interuniversity Institute for Biostatistics and Statistical Bioinformatics, University Hasselt, Agoralaan Building D, \\ 3590 Diepenbeek, Belgium; cui.wang@effem.com; guangtao.zhang@effem.com
}

Received: 21 June 2020 / Accepted: 25 November 2020

(c) 2021 Wageningen Academic Publishers

OPEN ACCESS CC) (i) (9) RESEARCH ARTICLE

\begin{abstract}
India is the largest jute and fifth largest maize producing country in the world. In India maize is commonly stored and transported in jute bags which are used multiple times. Aflatoxin contamination of maize is a major issue in India. This study evaluated the potential impact of re-using jute bags on the risk of aflatoxin contamination of maize in the food supply chain. A total of 121 jute bags were collected in India; 95 had been used for maize and 26 bags were new. Significantly higher numbers of viable aflatoxigenic fungi were counted from re-used bags (27.8 times) $(P<0.05)$, than the number from new bags. There was no significant difference between aflatoxin concentration found in the re-used jute bags and the new jute bags $(P>0.05)$. Further analysis revealed that the aflatoxigenic fungal population (3.0 times) and aflatoxin concentration (1.2 times) were significantly higher in jute bags that had been used for maize with higher aflatoxin contamination $(14-188.4 \mu \mathrm{g} / \mathrm{kg}$ total aflatoxins) than in those that had been used for maize with lower contamination $(0.8-5.4 \mu \mathrm{g} / \mathrm{kg}$ total aflatoxins) $(P<0.05)$. The significant positive correlation $(P<0.05)$ between the aflatoxigenic fungal population of used jute bags and aflatoxin contamination of their packed maize indicated there is a risk of cross-contamination in the supply chain introduced by re-using jute bags. This is the first study to systematically reveal the potential impact of re-using jute bags on the fungal population and aflatoxin contamination risk. The application of readily applied treatments to re-used jute bags would help to minimise the aflatoxin contamination.
\end{abstract}

Keywords: aflatoxigenic fungi, total aflatoxins, maize, re-used jute bag

\section{Introduction}

Aflatoxins are a group of highly toxic compounds produced mainly by Aspergillus flavus and Aspergillus parasiticus. Aflatoxin $B_{1}$ can cause liver cancer (Ostry et al., 2017). Aflatoxins have become a global food security risk affecting the whole food supply chain due to globalisation and e-commercialisation (Klingelhofer et al., 2018). Data from the Center for Disease Control in the USA indicate that more than 4.5 billion people in developing countries are at risk of exposure to aflatoxins in their food supply (CDC, 2012).

Conditions leading to the biosynthesis of aflatoxins are complex. Nevertheless, numerous studies have demonstrated that aflatoxin production by fungi is typically influenced by drought stress, a combination of heat and humidity, and food or feed substrates (Amare and Keller, 2014; Chang et al., 2005; Fountain et al., 2018; Nierman, et al., 2015; Villers, 2014). Major geographic and regional differences in climate conditions may help explain why many countries in Africa and Asia show much more severe aflatoxin contamination than North America and European countries (Palliyaguru and $\mathrm{Wu}, 2013)$. Well-designed agricultural and food processing systems can greatly reduce the food safety risks associated with aflatoxin and other mycotoxins (Kumar et al., 2017). Current principles for aflatoxin risk management in the field focus mainly on the weather conditions during the pre-harvest period, the temperature and humidity 
during post-harvest (including storage and transportation), biological control, and crop breeding (Mahuku et al., 2019; Paramawati et al., 2016; Yu, 2012). However, specific conventional practices in agronomy and supply chain management are different between countries and regions. People are less exposed to aflatoxins in developed countries due to better practices and stricter regulations than in many developing countries. Fungal growth and mycotoxin contamination are serious issues for many foods and feedstuffs in developing countries; contamination can then be exacerbated by improper post-harvest practices during storage, packaging and processing (James and Zikankuba, 2018; Wu and Khlangwiset, 2010). The influence of different conventional practices on aflatoxin risk in the food supply chain, e.g. packaging materials used during storage and distribution, has attracted increasing attention (Udomkun et al., 2017).

Significant resources are invested annually by the food production industry to source and test raw materials (including in-bound acceptance testing at the factory gate) to avoid using aflatoxin contaminated ingredients in food products. Aflatoxin contamination is a major reason for the rejection of many raw materials with high value or usage volume, such as peanuts and maize; large scale rejection of raw materials can disrupt factory production and corresponding business plans (Baker et al., 2014). This is an issue in the major maize production country, India, where it has been noted that maize production has a high food safety risk due to aflatoxin contamination (Rajarajan et al., 2013). Human consumption of maize is much higher in India ( $28 \%$ of total maize production) than in other developed countries where the bulk of maize produced is used as a raw material for the extraction and fermentation industry (Murdock and Baoua, 2014; Ranum et al., 2014). The high human consumption of maize in India drives a particularly urgent demand for aflatoxin management. The reported high aflatoxin contamination levels of maize in India provided an opportunity for a case study to identify potential supply-chain causes for aflatoxin contamination beyond well-established variables such as climate and geographic location. One conventional supply chain practice in India, re-use of jute bags for both storage and transportation of maize, was identified as a potential factor that could contribute to aflatoxin contamination. This practice was the focus of this study.

Jute is one of the strongest and most affordable natural fibres available, leading to its common use in storage bags for many crops including rice, wheat, maize, cocoa beans, and coffee beans. About $98 \%$ of world jute was grown in India and Bangladesh in 2017 (FAO, 2019). India is the world's largest producer of jute and contributes more than half $(55.7 \%)$ of the world's total production. India and Bangladesh are also countries that utilise significant quantities of jute fibre and products. Indian and Bangladeshi regulations require that most food grains produced for the domestic market are packed in jute bags; this strategy may be designed to support their position as the world's leading jute producers and to help support the jute sector. Jute is considered to be very suitable for bulk packaging of agricultural commodities due to its biodegradability and versatility (Maity, 2016). However, the strength of jute decreases in humid climates or when exposed to shifts in environment, resulting in susceptibility to microbial attack (Ferreira et al., 2016).

Some studies have demonstrated that jute bags are superior to plastic woven bags for peanut storage, whereas others found no evidence of improved antimicrobial effects when jute bags were compared to plastic woven bags (Bulaong, 2002; Wagacha et al., 2013). Jute bags are commonly reused in the supply chain due to environmental and cost considerations, and re-use of jute bags in the maize supply chain is a typical practice in India (Bari et al., 2012). The practice of transporting and storing maize in re-used jute bags continues throughout the supply chain, extending to individual consumers as well as food production facilities.

Previous studies have assessed the potential effects on the fungal population and aflatoxin contamination of maize stored in bags made of different materials, such as jute, polypropylene and polyethylene, under various storage conditions. However, most of these studies were making assessments based on new bags (Malaker et al., 2008; Mutegi et al., 2013; Nakai et al., 2008; Suanthie et $a l ., 2009)$. To date there has been no systematic research that specifically assessed the carried over aflatoxigenic fungal populations and aflatoxin contamination of jute bags after they had been used for maize storage. These were the objectives in this study.

\section{Materials and methods}

\section{Jute bag sampling in India}

Jute bags previously used for maize transportation and storage were collected from maize suppliers in Telangana, India ('re-used': n=95). Re-used jute bags were randomly collected from 54 batches of packed maize (with approximately $50 \mathrm{~kg}$ of maize packed in one jute bag, five tons of maize per batch). New jute bags were bought from two local stores that only sell new and used jute bags in Telangana, India as controls ('new': $n=26$ ). Further classification of the re-used jute bags was based on in-bound acceptance testing of individual batches of maize. In-bound acceptance tests were conducted to evaluate the aflatoxin concentration of maize packed in these jute bag samples, using the standard protocol for Ridascreen ${ }^{\oplus} \mathrm{FAST}$ Aflatoxin (R-Biopharm AG, Darmstadt, Germany). Bags from maize batches with aflatoxin concentration lower than $12 \mu \mathrm{g} / \mathrm{kg}$ were grouped as 'released' $(\mathrm{n}=26)$, whilst 
bags from maize with aflatoxin concentration higher than $12 \mu \mathrm{g} / \mathrm{kg}$ were grouped as 'rejected' ( $\mathrm{n}=69)$.

Each jute bag sample was considered as a rectangle and evenly divided into six smaller rectangles from one side and a further six from the reverse side. A square cloth $(20 \mathrm{~cm} \times 20 \mathrm{~cm})$ was cut evenly in the middle of each small rectangle using sterilised scissors, resulting in a total of 12 sub-samples of material from each jute bag sample. These sub-samples were subsequently cut into small fibres using a Fellowes paper shredder 99MS (Fellowes, Itaska, IL, USA). The small fibres were collected carefully and mixed thoroughly as one sample.

\section{Total Aspergillus flavus and Aspergillus parasiticus fungal isolation from jute bags}

The isolation method was based on that developed by Pitt et al. (1983), with modifications. A. flavus and A. parasiticus agar (AFPA) plates were prepared using AFPA base (Oxoid, Basingstoke, UK) with additional chloramphenicol supplementation (Oxoid) (final concentration $100 \mathrm{mg} / \mathrm{l}$ ). $25 \mathrm{~g}$ fibres from the jute bag samples were weighed and transferred into sterile distilled water $(225 \mathrm{ml})$ at room temperature, whilst stirring at $1.1 \times g$. After $1 \mathrm{~h}$, the mixed solution $(200 \mu \mathrm{l})$ with serial dilutions $\left(10^{0}, 10^{-1}\right.$, and $\left.10^{-2}\right)$ was inoculated onto AFPA plates. Three replicate plates were used per dilution. The inoculated AFPA plates were incubated at $30^{\circ} \mathrm{C}$ for three days. The total population of A. flavus and A. parasiticus group fungi of each new or used jute bag was determined by the dilution applied, the average number of orange colonies on the AFPA, and the amount of aliquot plated.

\section{Aflatoxigenic fungal isolation from jute bags}

A visible fluorescence determination method was applied with modifications to further separate aflatoxigenic and non-aflatoxigenic fungi (Dyer and Mccammon, 1994; Franco et al., 1998). Coconut cream agar (CCA) was prepared using 50\% coconut milk (Real Thai; Thaitan Foods International Co., Ltd., Bangkok, Thailand) and 1.5\% agar (BD, Sparks, MD, USA). The edges of all the orange colonies on AFPA plates were cut and inoculated onto individual CCA plates, which were incubated at $30^{\circ} \mathrm{C}$. After 7 days, UV light $(365$ $\mathrm{nm}$ ) was used to differentiate between toxigenic and nontoxigenic fungi. To avoid false results, aflatoxin production of suspect toxigenic fungi selected from the CCA plates was confirmed using the Romer ELISA kit AgraQuant Total Aflatoxin Assay 1/20 (Romer Labs GmbH, Tulln, Austria). A. flavus NRRL 3357 was obtained from the American Type Culture Collection (ATCC, Manassas, VA, USA) and used as the toxigenic reference strain for AFPA isolation (orange), and CCA (fluorescence). Negative controls were empty AFPA or CCA plates (three replicates).

\section{Analysis of aflatoxin concentration of jute bags}

ELISA was used for aflatoxin analysis of the jute bags. A sample (10 g) of the homogenised fibres from each jute bag was extracted with $80 \%$ methanol $(100 \mathrm{ml})$ (Agilent Technologies, Santa Clara, CA, USA) whilst stirring for 20 min over a magnetic stirrer. The extraction solution was collected and filtered using a $0.45 \mu \mathrm{m}$ filter membrane (Agilent Technologies). The filtered extraction solution was cleaned-up following the standard protocol for Romer AflaStar" $\mathrm{R}$ immunoaffinity Columns (Romer Labs $\mathrm{GmbH}$ ). The cleaned-up aflatoxin extraction solution was diluted to $70 \%$ methanol and used for ELISA tests to determine the aflatoxin concentration in the jute bag samples, using the standard protocol for the Romer ELISA kit AgraQuant Total Aflatoxin Assay 1/20 (Romer Labs GmbH). The OD absorbance was measured at $450 \mathrm{~nm}$ and $630 \mathrm{~nm}$ using a Synergy H1 Hybrid Multi-Mode Reader (BioTek, Winooski, VT, USA).

\section{Validation of analytical method for quantification of aflatoxins}

The performance of sample extraction and the ELISA method was validated before analysis of the experimental samples. A new jute bag with tested aflatoxin concentration of ' $0 \mu \mathrm{g} / \mathrm{kg}$ ' by the ELISA method mentioned above was selected as the 'blank'. Recovery experiments were performed by spiking the blank jute bag samples ( $10 \mathrm{~g}$ of each) and jute bag samples (10 $\mathrm{g}$ of each from the same bag used for the blank) with aflatoxin standard (Romer Labs) to obtain an aflatoxin concentration of 1.0, 1.5, 2.0, 2.5, and $3.0 \mu \mathrm{g} / \mathrm{kg}$. Spiked samples were incubated in air overnight at room temperature, followed by sample extraction and ELISA testing as described above. All samples were analysed in three replicates. The recovery rates of aflatoxins were $76.4 \%$ with a relative standard deviation (RSD) of $9.3 \%$ for the jute bags.

\section{Statistical analysis}

Mixed effects models were used to investigate differences between the jute bag types. A random batch effect and a fixed effect of jute bag-group was used. Square root transformation of the outcomes was modelled to meet the assumptions of normality of the residuals. Furthermore, a bag-type specific residual error variability was specified to deal with a larger variability in the outcomes of the rejected jute bags, compared to the released and new bags. Pairwise comparisons between the groups of jute bag were corrected for multiple testing by means of a Bonferroni correction.

Associations between the outcomes in the jute bag (aflatoxin concentration, aflatoxigenic fungi) and the aflatoxin concentration in packed maize were investigated 
using a regression model. This model incorporated a random batch effect and a fixed effect for the aflatoxin concentration of packed maize. The regression slope was allowed to be jute bag type specific by means of an interaction term. A $5 \%$ level of significance and a $1 \%$ level of very significance were used, and statistical analyses were performed in SAS for windows version 9.4 (SAS, Cary, NC, USA).

\section{Results}

\section{Aflatoxin contamination of maize packed in jute bags}

The average aflatoxin concentration of the 48 different maize batches that were packed in the sampled jute bags was $32.2 \mu \mathrm{g} / \mathrm{kg}$ (Figure 1). The total aflatoxin concentration of the packed maize was used to group the released or rejected maize batches and their corresponding jute bags (below or above $12.0 \mu \mathrm{g} / \mathrm{kg}$ ). As there were some batches of maize with severe contamination, the maize packed in rejected jute bags showed a broad range of aflatoxin concentrations from 13.3 to $188.4 \mu \mathrm{g} / \mathrm{kg}$, with a median value of $41.6 \mu \mathrm{g} / \mathrm{kg}$. The maize in released samples showed a narrow range of concentrations from 0.8 to $5.4 \mu \mathrm{g} / \mathrm{kg}$, with the median value of $1.1 \mu \mathrm{g} / \mathrm{kg}$ (Figure 1). The average aflatoxin concentration of maize packed in rejected jute bags $(57.8 \mu \mathrm{g} / \mathrm{kg})$ was significantly different to that in released jute bags $(2.0 \mu \mathrm{g} / \mathrm{kg})(P<0.01)$.

In general, larger variability in the aflatoxin concentration of packed maize was observed in the rejected jute bags (standard deviation [SD] of $47.2 \mu \mathrm{g} / \mathrm{kg}$ ) compared to the released bags (SD of $2.0 \mu \mathrm{g} / \mathrm{kg}$ ). This feature of the data was reflected in the model by specifying a bag-type specific random intercept variability and residual error variability.

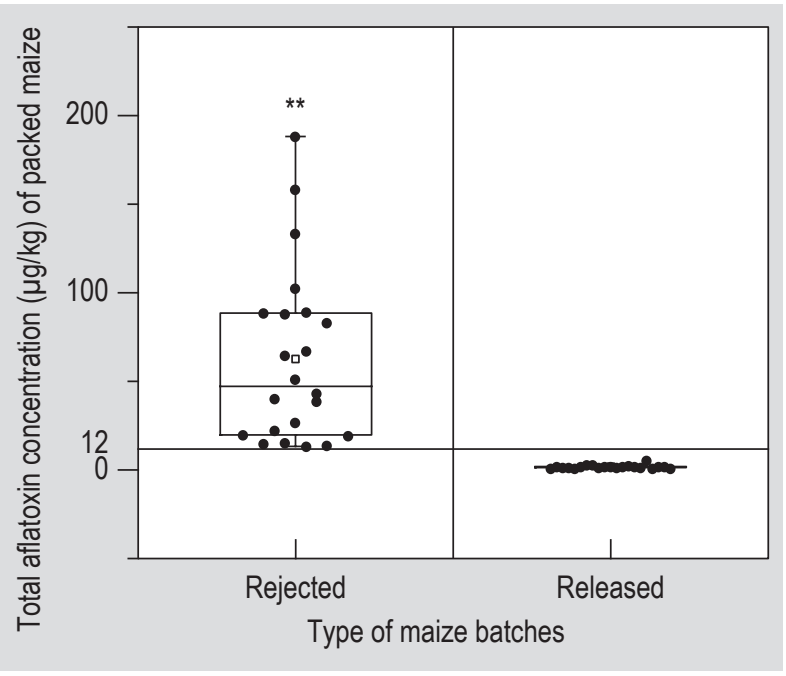

Figure 1. Aflatoxin concentration distribution of maize packed in the re-used jute bags. ${ }^{*}{ }^{*} P<0.01$.

\section{Analysis of aflatoxin concentration of jute bags}

The average aflatoxin concentration of all the re-used jute bags $(4.0 \mu \mathrm{g} / \mathrm{kg})$ was 1.6 times that of the new jute bags $(2.6 \mu \mathrm{g} / \mathrm{kg})$ (Figure 2A), however, this difference was not statistically significant $(P>0.05)$. Further analysis demonstrated that the rejected bags had significantly higher concentration of aflatoxin ( $4.7 \mu \mathrm{g} / \mathrm{kg}, 1.2$ times) than released ones $(2.1 \mu \mathrm{g} / \mathrm{kg})(P<0.05)$ (Figure 2B). There was no significant difference in the concentration of aflatoxin between new and released jute bags $(P>0.05)$ (Figure 2). In general, the aflatoxin concentrations detected in the new or re-used jute bags were considerably lower than the concentrations detected in the packed maize (Figure 1, Figure 2A).

The aflatoxin concentrations of the packed maize did not affect the aflatoxin concentration of the jute bags that had been used for storage and transportation. The association between aflatoxin concentrations of packed maize and aflatoxin concentrations of re-used jute bags is not statistically significant $(P>0.05)$, further demonstrating the low cross contamination risk upon the reusing practice from the leftover aflatoxins in re-used jute bags.

\section{Total Aspergillus flavus and Aspergillus parasiticus fungal population of jute bags}

Differences were noted in the populations of total A. flavus and $A$. parasiticus isolated from the re-used and new jute bags (Figure 3). Very significantly higher numbers of viable A. flavus and A. parasiticus fungi were counted from reused bags $\left(4.5 \times 10^{3}\right.$ colony forming units $\left.(\mathrm{cfu}) / \mathrm{g}\right)(P<0.01)$; this was 19.5 times higher than the number from new bags $\left(2.2 \times 10^{2} \mathrm{cfu} / \mathrm{g}\right)($ Figure 3A). The viable count of $A$. flavus and $A$. parasiticus fungi $\left(5.4 \times 10^{3} \mathrm{cfu} / \mathrm{g}\right)$ from rejected jute bags was 2.0 times higher than that from the released jute bags $\left(1.8 \times 10^{3} \mathrm{cfu} / \mathrm{g}\right)$ and 23.5 times higher than that from the new jute bags (Figure 3B). P50 of the dataset from rejected jute bags $\left(1.6 \times 10^{3} \mathrm{cfu} / \mathrm{g}\right)$ was similar to that from released bags $\left(1.5 \times 10^{3} \mathrm{cfu} / \mathrm{g}\right)$, and much higher than that from new bags $\left(7.0 \times 10^{1} \mathrm{cfu} / \mathrm{g}\right)$. There were significant differences between the total $A$. flavus and $A$. parasiticus fungal population isolated from rejected jute bags and new bags $(P<0.01)$, and between released jute bags and new bags $(P<0.05)$, indicating that upon usage, the jute bags carried more fungi to cause potential risks. However, the difference between the viable count of total A. flavus and $A$. parasiticus fungi from released jute bags and rejected ones was not statistically significant $(P>0.05)$ (Figure $3 \mathrm{~B})$.

\section{Analysis of the aflatoxigenic fungal population of jute bags}

Since not all of A. flavus and A. parasiticus produce aflatoxins, isolation of non-toxigenic and toxigenic fungal population was qualitatively investigated by the combined 

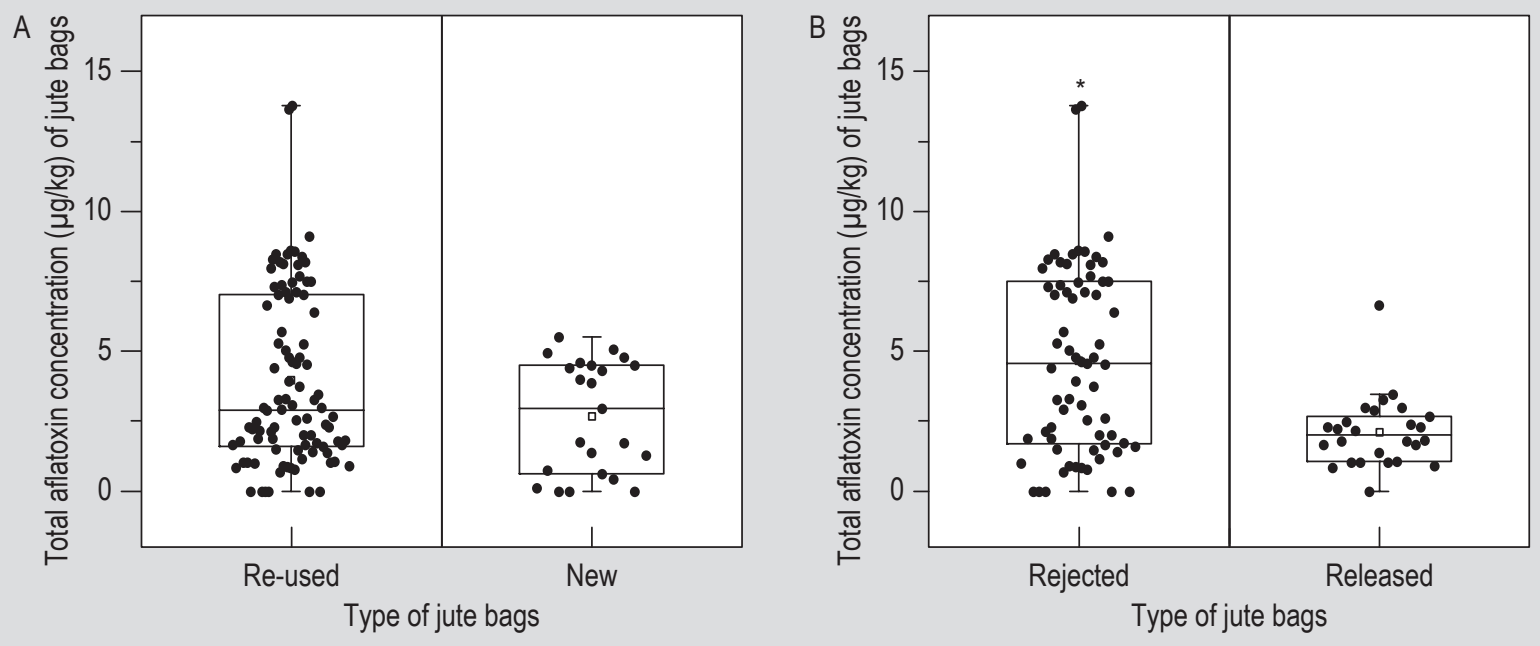

Figure 2. Aflatoxin concentration distribution of jute bags samples divided into different groups: (A) new and re-used bags; (B) rejected and released bags. ${ }^{*} P<0.05$.
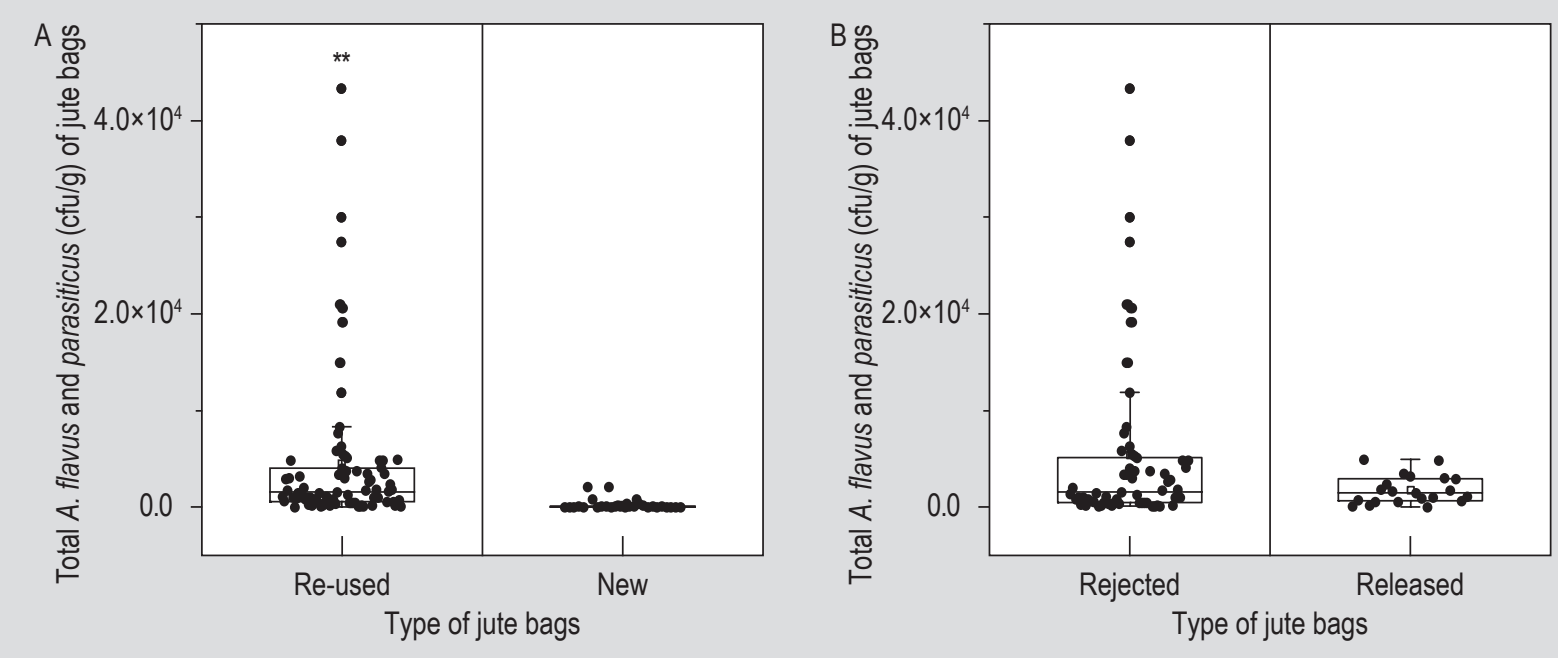

Figure 3. Comparison of total Aspergillus flavus and Aspergillus parasiticus fungal population isolated from jute bags divided into different groups: (A) new and re-used bags; (B) released and rejected bags. ${ }^{* *} P<0.01$.

cultural assay and confirmed by the ELISA immunoassay. Differences were noted in the populations of aflatoxigenic A. flavus and A. parasiticus isolated from the re-used and new jute bags (Figure 4). The number of viable aflatoxigenic fungi isolated from re-used bags $\left(2.3 \times 10^{3} \mathrm{cfu} / \mathrm{g}\right)$ was 27.4 times higher than the number from new bags $(80 \mathrm{cfu} / \mathrm{g})$ $(P<0.01)$ (Figure $4 \mathrm{~A})$. The viable count of aflatoxigenic fungi from released $\left(0.7 \times 10^{3} \mathrm{cfu} / \mathrm{g}\right)$ and rejected $\left(2.8 \times 10^{3} \mathrm{cfu} / \mathrm{g}\right)$ jute bags was very significantly higher than that from the new jute bags ( 7.7 times and 34.0 times; $P<0.01$ ). These results confirmed that toxic fungi could be carried over in jute bags when reusing.

The viable count in rejected bags was also significantly higher (3.0 times) than that of the released jute bags $(P<0.05)$ (Figure 4B). When further investigating by using the regression model, the statistical result showed a very significant association between the aflatoxin concentration of packed maize and leftover aflatoxigenic fungi population of the re-used jute bags $(P<0.01)$, further demonstrating the high cross contamination risk upon the re-using practice from the leftover aflatoxigenic fungi in re-used jute bags.

\section{Discussion}

Post-harvest controls play a critical role in managing mycotoxin risk in food and agriculture. Good storage and packaging practices have been emphasised for many years for mycotoxin control. There are many studies on improving packaging materials and storage condition control strategies, e.g. the PICS bags trials in Africa (Murdock and Baoua, 2014). However, the widespread re-use of jute 


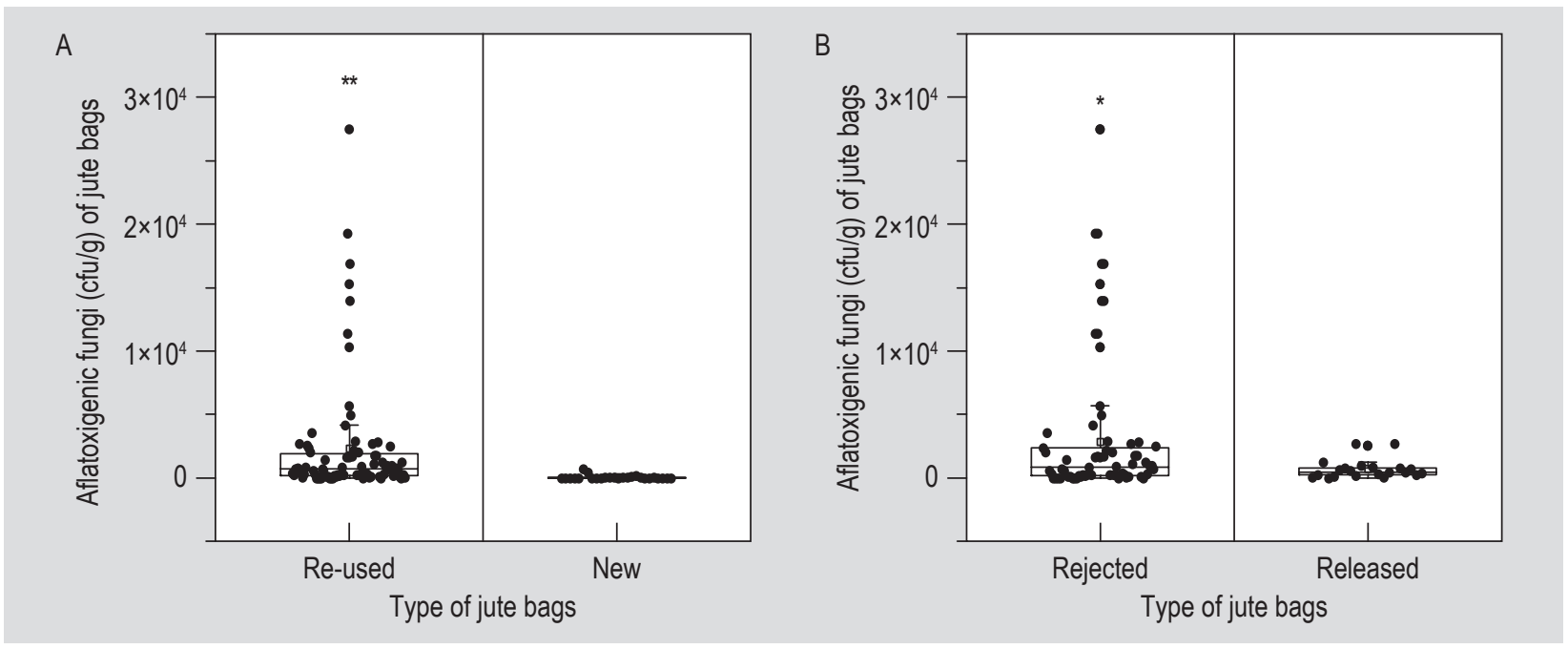

Figure 4. Comparison of toxigenic Aspergillus flavus and Aspergillus parasiticus fungal population isolated from jute bags divided into different groups: (A) new and re-used bags; (B) released and rejected bags. ${ }^{*} P<0.05$; ${ }^{*} P<0.01$.

bags has barely attracted attention by researchers, despite being a conventional practice in many countries in the food supply chain.

Maize is the third most important food crop worldwide, after rice and wheat. This is also true of India and Bangladesh (Ranum et al., 2014). In this study the significantly higher residual total and aflatoxigenic fungal populations were detected in jute bags after they had been packed with maize batches with high aflatoxin contamination $(P<0.01)$. However, the aflatoxin concentrations of these used jute bags were very low. To date, no report has shown that aflatoxigenic fungi can grow and produce aflatoxins with jute fibre. Regarding the porous and the absorptive feature of jute bags (Sudini et al., 2015), when used previously for maize storage, jute bags can easily trap and absorb the damaged maize kernels and dust that can contain a high level of aflatoxins and aflatoxigenic fungi (Hoffmann et al., in press), further resulting in the detection of aflatoxins and aflatoxigenic fungi in the damaged maize kernel-colonised jute bags. Previous studies demonstrating that the nutrient composition and content of defatted substrates affects the accumulation of aflatoxins, help to explain the result in this study (Liu et al., 2016). It is likely that the growth and aflatoxin production of fungi on jute bags were delayed due to lack of optimal nutrition. In this study very low amounts of both aflatoxins and aflatoxigenic fungi were detected in samples from some new jute bags. This may be due to environmental exposure after manufacture, and the porous and the absorptive features of jute bags.

The development of aflatoxigenic fungi will be fostered when contacting with their preferred hosts, e.g. maize, and highly correlated with extraneous temperature and moisture. Therefore, jute bag with large numbers of aflatoxigenic fungi, e.g. from a rejected maize batch, has the potential to spread aflatoxigenic fungi remaining in it to another maize batch when re-using. When stored under improper storage conditions, e.g. temperature ranged from $25-30{ }^{\circ} \mathrm{C}$ and moisture content above $34 \%$ (Giorni et al., 2007), growth of aflatoxigenic fungi and aflatoxin contamination risk of this maize batch increases. A similar study has been reported by Mutegi et al. (2013), which demonstrated that peanut kernels stored in jute bags under improper conditions showed increased aflatoxin contamination risks.

This study included a larger sample size (48) of packed maize compared to a previous study in the Indian market. $31 \%$ of the packed maize batches sampled exceeded the Indian limit of $30 \mu \mathrm{g} / \mathrm{kg}$ for aflatoxins, which was similar to the previous study (Somashekar et al., 2004). Somashekar et al. (2004) isolated A. flavus and A. parasiticus fungi from different food and feed commodities. The authors reported a range of $0-100 \times 10^{3} \mathrm{cfu} / \mathrm{g}$, with the highest number from maize; a range of $1-43 \times 10^{3} \mathrm{cfu} / \mathrm{g}$ was found in jute bags with the highest number from jute bags used for rejected maize batches, thus reflecting the higher risk and potential of residual fungi when jute bags are used for storage and transportation of maize. In addition, the median ratio of isolated aflatoxigenic to non-aflatoxigenic fungi (50\%) from the rejected jute bags was higher than the reported aflatoxigenic fungi ratio from maize field soil (approximately 40\%) (Razzaghiabyaneh et al., 2006). Comparable ratios found in released (33\%) and new jute bags (25\%) were lower. These findings would be expected because maize is the preferred fungal host, and the more highly contaminated maize batches may contain more viable aflatoxigenic strains than batches with lower contamination. The higher aflatoxigenic fungi ratio in re-used jute bags compared with that from new bags further supports the aflatoxin contamination risk associated with re-using jute bags. 
This study was a preliminary evaluation of the aflatoxin risks associated with re-used jute bags. The results confirmed the aflatoxin concentration of packed maize as a predictor of the leftover aflatoxigenic fungi of these used jute bags, which would bring an increased aflatoxigenic fungi to supply chain when re-using according to a more severe contamination condition of previously packed maize by aflatoxins. The outcomes may be used to improve mycotoxin management systems in the future to support food security. Whilst these data suggest that stopping the reuse of jute bags may be beneficial, this may not be realistic due to cost, environmental and regulatory considerations in various countries. There are many aflatoxin or fungal decontamination methods reported, such as ozonisation, ammonization, fumigation, biocontrol, irradiation, and using certain hermetic storage methods instead of jute sacks (Allameh et al., 2005; Basaran and Akhan, 2010; Beuchat et al., 1999; Mannaa et al., 2017; Murdock and Baoua, 2014). Measures to reduce the risk of cross contamination are of value, this study undertook preliminary evaluation of some simple treatments to counteract this problem. The preliminary results showed that both the ozone and ultraviolet treatments decreased the number of residual aflatoxigenic fungi in the re-used jute bags to certain extent, confirming the possibility that cross contamination from reused jute bags could be reduced by ozonisation and irradiation. Additional practical treatments such as vacuum and heat, will be evaluated in future studies. An alternative approach through development of a strategy that involves decontamination of the potential inoculation source could substantially reduce the impact of jute bag re-use on supply and farm economics.

Jute bags are also widely used for the transport and storage of other raw materials including coffee beans, peanuts and cocoa beans in many countries and regions (Broissinvargas et al., 2018). Other types of food contamination, e.g. mineral oil, mould, and insects have also been reported in jute bags (Abdelghany et al., 2016; Grob et al., 1991). These potential risks are also worthy to be assessed and managed in the food supply chain.

This study has investigated the aflatoxin contamination and the presence of aflatoxigenic fungi in jute bags used for the storage and transportation of maize. The study identified that re-using jute bags may be a factor increasing the risk of aflatoxin contamination in the raw material supply chain. Developing an applicable treatment to 'clean-up' the re-used jute bags are recommended to control the risk. These data may facilitate aflatoxin prevention and risk management in India and other countries, shedding more light on the impact this agricultural practice may have on the safety of the food supply chain.

\section{Acknowledgements}

The authors are grateful for the statistical support from Dr John Carney, and editorial input from Peter Markwell and Dr Jagger Harvey.

\section{Conflicts of Interest}

The authors declare no conflict of interest.

\section{References}

Abdelghany, A.Y., Awadalla, S.S., Abdelbaky, N.F., Elsyrafi, H.A. and Fields, P.G., 2016. Efficacy of reduced risk insecticides on penetration into jute and polyethylene bags by Lasioderma serricorne (F.) (Coleoptera: Anobiidae). Journal of Stored Products Research 69: 190-194. http://doi.org/10.1016/j.jspr.2016.08.009

Allameh, A., Safamehr, A., Mirhadi, S.A., Shivazad, M., Razzaghiabyaneh, M. and Afsharnaderi, A. 2005. Evaluation of biochemical and production parameters of broiler chicks fed ammonia treated aflatoxin contaminated maize grains. Animal Feed Science and Technology 122: 289-301. http://doi.org/10.1016/j. anifeedsci.2005.03.005

Amare, M.G. and Keller, N.P., 2014. Molecular mechanisms of Aspergillus flavus secondary metabolism and development. Fungal Genetics and Biology 66: 11-18. http://doi.org/10.1016/j. fgb.2014.02.008

Baker, R.C., Ford, R.M., Helander, M.E., Janusz, M., Ramesh, N. and Bonnie, R., 2014. Framework for managing mycotoxin risks in the food industry. Journal of Food Protection 77: 2181-2188. http:// doi.org/10.4315/0362-028X.JFP-14-060

Bari, Q.H., Hassan, K.M. and Haque, R., 2012. Scenario of solid waste reuse in Khulna city of Bangladesh. Waste Management 32: 25262534. http://doi.org/10.1016/j.wasman.2012.07.001

Basaran, P. and Akhan, U., 2010. Microwave irradiation of hazelnuts for the control of aflatoxin producing Aspergillus parasiticus. Innovative Food Science and Emerging Technologies 11: 113-117. https://doi. org/10.1016/j.ifset.2009.08.010

Beuchat, L.R., Chmielewski, R., Keswani, J., Law, S.E. and Frank, J.F., 1999. Inactivation of aflatoxigenic Aspergilli by treatment with ozone. Letters in Applied Microbiology 29: 202-205. http://doi. org/10.1046/j.1365-2672.1999.00618.x

Broissinvargas, L.M., Snellcastro, R., Godon, J., Gonzalezrios, O. and Suarezquiroz, M.L., 2018. Impact of storage conditions on fungal community composition of green coffee beans Coffea arabica L. stored in jute sacks during 1 year. Journal of Applied Microbiology 124: 547-558. https://doi.org/10.1111/jam.13656

Bulaong, S.S.P., 2002. Fungal population, aflatoxin and free fatty acid contents of peanuts packed in different bag types. Biotropia 19: 1-25. http://doi.org/10.11598/btb.2002.0.19.229

Centers for disease control and prevention (CDC), 2012. Health studies - understanding chemical and radiation exposures: aflatoxin. Available at: https://www.cdc.gov/nceh/hsb/chemicals/aflatoxin.htm 
Chang, P., Horn, B.W. and Dorner, J.W., 2005. Sequence breakpoints in the aflatoxin biosynthesis gene cluster and flanking regions in nonaflatoxigenic Aspergillus flavus isolates. Fungal Genetics and Biology 42: 914-923. http://doi.org/10.1016/j.fgb.2005.07.004

Dyer, S.K. and Mccammon, S., 1994. Detection of toxigenic isolates of Aspergillus flavus and related species on coconut cream agar. Journal of Applied Microbiology 76: 75-78. http://doi. org/10.1111/j.1365-2672.1994.tb04418.x

Ferreira, J.A.M., Capela, C., Manaia, J. and Costa, J.D., 2016. Mechanical properties of woven mat jute/epoxy composites. Materials Research 19: 702-710. http://doi.org/10.1590/1980-5373-MR-2015-0422

Food and Agriculture Organization of the United Nations (FAO), 2019. Statistics. Available at: http://www.fao.org/faostatics/en

Fountain, J.C., Koh, J., Yang, L., Pandey, M.K., Nayak, S.N., Bajaj, P., Zhuang, W., Chen, Z., Kemerait, R.C. and Lee, R.D., 2018. Proteome analysis of Aspergillus flavus isolate-specific responses to oxidative stress in relationship to aflatoxin production capability. Scientific Reports 8: 3430. http://doi.org/10.1038/s41598-018-21653-x

Franco, C.M., Fente, C.A., Vazquez, B.I., Cepeda, A., Mahuzier, G. and Prognon, P., 1998. Interaction between cyclodextrins and aflatoxins $\mathrm{Q}_{1}, \mathrm{M}_{1}$ and $\mathrm{P}_{1}$ fluorescence and chromatographic studies. Journal of Chromatography A 815: 21-29. http://doi.org/10.1016/S00219673(98)00509-3

Giorni, P., Magan, N., Pietri, A., Bertuzzi, T. and Battilani, P., 2007. Studies on Aspergillus section Flavi isolated from maize in northern Italy. International Journal of Food Microbiology 113: 330-338. https://doi.org/10.1016/j.ijfoodmicro.2006.09.007.

Grob, K., Lanfranchi, M., Egli, J. and Artho, A., 1991. Determination of food contamination by mineral oil from jute sacks using coupled LC-GC. Journal of the Association of Official Analytical Chemists International 74: 506-512.

Hoffmann, V., Mutiga, S.K., Harvey, J.W., Nelson, R.J. and Milgroom, M.G., in press. Observability of food safety losses in maize: evidence from Kenya. Food Policy, 101895. https://doi.org/10.1016/j. foodpol.2020.101895

James, A. and Zikankuba, V.L., 2018. Mycotoxins contamination in maize alarms food safety in sub-Sahara Africa. Food Control 90: 372-381. http://doi.org/10.1016/j.foodcont.2018.03.018

Klingelhofer, D., Zhu, Y., Braun, M., Bendels, M.H.K., Bruggmann, D. and Groneberg, D.A., 2018. Aflatoxin - Publication analysis of a global health threat. Food Control 89: 280-290. https://doi. org/10.1016/j.foodcont.2018.02.017

Kumar, P., Mahato, D.K., Kamle, M., Mohanta, T.K. and Kang, S.G., 2017. Aflatoxins: a global concern for food safety, human health and their management. Frontiers in Microbiology 7: 2170. http:// doi.org/10.3389/fmicb.2016.02170

Liu, J., Sun, L., Zhang, N., Zhang, J., Guo, J., Li, C., Rajput, S.A. and Qi, D. 2016. Effects of nutrients in substrates of different grains on aflatoxin $\mathrm{B}_{1}$ production by Aspergillus flavus. BioMed Research International 2016: 7232858. http://doi.org/10.1155/2016/7232858

Mahuku, G., Nzioki, H.S., Mutegi, C., Kanampiu, F., Narrod, C.A. and Makumbi, D., 2019. Pre-harvest management is a critical practice for minimizing aflatoxin contamination of maize. Food Control 96: 219-226. http://doi.org/10.1016/j.foodcont.2018.08.032
Maity, S., 2016. Jute needlepunched nonwovens: manufacturing, properties, and applications. Journal of Natural Fibers 13: 383-396. http://doi.org/10.1080/15440478.2015.1029200

Malaker, P.K., Mian, I.H., Bhuiyan, K.A., Akanda, A.M. and Reza, M.M.A., 2008. Effect of storage containers and time on seed quality of wheat. Bangladesh Journal of Agricultural Research 33: 469-477. http://doi.org/10.3329/bjar.v33i3.1606

Mannaa, M., Oh, J.Y. and Kim, K.D., 2017. Microbe-mediated control of Aspergillus flavus in stored rice grains with a focus on aflatoxin inhibition and biodegradation. Annals of Applied Biology 171: 376-392. http://doi.org/10.1111/aab.12381

Murdock, L.L. and Baoua, I.B., 2014. On Purdue improved cowpea storage (PICS) technology: background, mode of action, future prospects. Journal of Stored Products Research 58: 3-11. http:// doi.org/10.1016/j.jspr.2014.02.006

Mutegi, C., Wagacha, J.M., Christie, M.E., Kimani, J. and Karanja, L.W., 2013. Effect of storage conditions on quality and aflatoxin contamination of peanuts (Arachis hypogaea L.). International Journal of AgriScience 3: 746-758.

Nakai, V.K., Rocha, L.O., Goncalez, E., Fonseca, H., Ortega, E.M.M. and Correa, B., 2008. Distribution of fungi and aflatoxins in a stored peanut variety. Food Chemistry 106: 285-290. http://doi. org/10.1016/j.foodchem.2007.05.087

Nierman, W.C., Yu, J., Fedorovaabrams, N.D., Losada, L., Cleveland, T.E., Bhatnagar, D., Bennett, J.W., Dean, R.A. and Payne, G.A., 2015. Genome sequence of Aspergillus flavus NRRL 3357, a strain that causes aflatoxin contamination of food and feed. Genome Announcements 3: e00168-15. http://doi.org/10.1128/ genomeA.00168-15

Ostry, V., Malir, F., Toman, J. and Grosse, Y., 2017. Mycotoxins as human carcinogens - the IARC monographs classification. Mycotoxin Research 33: 65-73. http://doi.org/10.1007/s12550016-0265-7

Palliyaguru, D.L. and Wu, F., 2013. Global geographical overlap of aflatoxin and hepatitis $\mathrm{C}$ : controlling risk factors for liver cancer worldwide. Food Additives and Contaminants Part A 30: 534-540. http://doi.org/10.1080/19440049.2012.751630

Paramawati, R., Widodo, P., Budiharti, U. and Handaka, H., 2016. The role of postharvest machineries and packaging in minimizing aflatoxin contamination in peanut. Indonesian Journal of Agricultural Science 7: 15-19. http://doi.org/10.21082/ijas. v7n1.2006.p15-19

Pitt, J.I., Hocking, A.D. and Glenn, D.R., 1983. An improved medium for the detection of Aspergillus flavus and A. parasiticus. Journal of Applied Microbiology 54: 109-114. http://doi. org/10.1111/j.1365-2672.1983.tb01307.x

Rajarajan, P.N., Rajasekaran, K.M. and Devi, N.K., 2013. Aflatoxin contamination in agricultural commodities. Indian Journal of Pharmaceutical and Biological Research 4: 148-151. http://doi. org/10.30750/ijpbr.1.4.25

Ranum, P., Penarosas, J.P. and Garciacasal, M.N., 2014. Global maize production, utilization, and consumption. Annals of the New York Academy of Sciences 1312: 105-112. https://doi.org/10.1111/ nyas.12396 
Razzaghiabyaneh, M., Shamsghahfarokhi, M., Allameh, A., Kazeroonshiri, A., Ranjbarbahadori, S., Mirzahoseini, H. and Rezaee, M., 2006. A survey on distribution of Aspergillus section Flavi in corn field soils in Iran: population patterns based on aflatoxins, cyclopiazonic acid and sclerotia production. Mycopathologia 161: 183-192. http://doi.org/10.1007/s11046-005-0242-8

Somashekar, D., Rati, E.R., Anand, S. and Chandrashekar, A., 2004. Isolation, enumeration and PCR characterization of aflatoxigenic fungi from food and feed samples in India. Food Microbiology 21: 809-813. http://doi.org/10.1016/j.fm.2004.01.012

Suanthie, Y., Cousin, M.A. and Woloshuk, C.P., 2009. Multiplex real-time PCR for detection and quantification of mycotoxigenic Aspergillus, Penicillium and Fusarium. Journal of Stored Products Research 45: 139-145. http://doi.org/10.1016/j.jspr.2008.12.001

Sudini, H., Ranga Rao, G.V., Gowda, C.L.L., Chandrika, R., Margam, V., Rathore, A. and Murdock, L.L., 2015. Purdue Improved Crop Storage (PICS) bags for safe storage of groundnuts. Journal of Stored Products Research 64: 133-138. https://doi.org/10.1016/j. jspr.2014.09.002
Udomkun, P., Wiredu, A.N., Nagle, M., Müller, J., Vanlauwe, B. and Bandyopadhyay, R., 2017. Innovative technologies to manage aflatoxins in foods and feeds and the profitability of application - a review. Food Control 76: 127-138. https://doi.org/10.1016/j. foodcont.2017.01.008

Villers, P., 2014. Aflatoxins and safe storage. Frontiers in Microbiology 5: 158-158. http://doi.org/10.3389/fmicb.2014.00158

Wagacha, J.M., Mutegi, C., Christie, M.E., Karanja, L.W. and Kimani, J., 2013. Changes in fungal population and aflatoxin levels and assessment of major aflatoxin types in stored peanuts (Arachis hypogaea Linnaeus). Journal of Field Robotics 2: 10-23.

Wu, F. and Khlangwiset, P., 2010. Health economic impacts and cost-effectiveness of aflatoxin-reduction strategies in Africa: case studies in biocontrol and post-harvest interventions. Food Additives and Contaminants Part A 27: 496-509. http://doi. org/10.1080/19440040903437865

Yu, J., 2012. Current understanding on aflatoxin biosynthesis and future perspective in reducing aflatoxin contamination. Toxins 4: 1024-1057. http://doi.org/10.3390/toxins4111024 
